\title{
Descolonizando o feminismo em Moçambique
}

\author{
Sexuality and Gender Politics in \\ Mozambique: Rethinking Gender \\ in Africa
}

ARNFRED, Signe.

Suffolk: Nordiska Afrikainstitutet; Uppsala: James Currey, 2011 . 310 p.

Em um momento crítico do desenvolvimento de meus próprios estudos sobre Moçambique, o livro de Signe Arnfred me chegou às mãos. Eu me via então encalacrado com os obstáculos conceituais que me faziam prisioneiro, frutos espúrios de uma trajetória que buscava passagem em meio à teoria antropológica clássica (estrutural-funcionalista) em direção a um ponto de vista crítico que refletisse, na interrogação sobre as relações de gênero e sexualidade, a superação do momento colonial em África.

Ora, a trajetória de pesquisa, o compromisso político e a reconfiguração conceitual que Signe Arnfred descreve e sustenta em seu denso livro mostraram em um só percurso a própria superação crítica que buscava, como modelo de descolonização de minha própria perspectiva sobre gênero e sexualidade, parentesco e casamento. Desiderato de uma relação de mais trinta anos com a sociedade moçambicana, uma relação, convém dizer, baseada no envolvimento pessoal com os problemas e as lutas das mulheres moçambicanas, o livro documenta tanto a própria trajetória de descolonização conceitual da autora quanto as mudanças no cenário político moçambicano, resultantes da transição entre o período socialista, marcado pelos slogans "abaixo" (ao tribalismo, à poligamia, ao feudalismo, aos curandeiros, ao lobolo, aos ritos de iniciação), com sua sanha por modernização e racionalização da sociedade, até o presente período neoliberal, marcado pelo programa de reestruturação econômica, ou "structural adjustment", imposto pelo Banco Mundial no anos 1990.

Arnfred chega a Maputo em 1981, acompanhada do marido, ela feminista, ambos militantes socialistas, buscavam participar do momento heroico de construção do socialismo pós-colonial em África. A autora emprega-se como socióloga na Organização da Mulher Moçambicana (OMM), a organização política surgida em 1973 como desdobramento da participação das mulheres na Luta de Libertação Nacional, configurada, a partir de 1965, por meio da criação do Destacamento Feminino do exército popular de libertação nacional. ${ }^{1}$ Trabalhando até 1984 na OMM, principalmente num grande esforço investigativo, preparatório para a Conferência Extraordinária da Organização, realizada em novembro desse mesmo ano, Arnfred pôde viajar pelo país e estabelecer contatos com dezenas de grupos de mulheres escutando suas demandas e discutindo seus problemas. Essa experiência marcou a perspectiva crítica da autora e tornou transparentes as contradições da política frelimista no que se referia às mulheres e às relações de gênero.

Na abertura da primeira Conferência da Mulher Moçambicana, realizada em março de 1973, portanto antes ainda da Independência, Samora Machel realiza discurso histórico: "A libertação da mulher é uma necessidade da revolução, garantia de sua continuidade, condição do seu triunfo". A OMM, entretanto, jamais se alinhou com uma perspectiva feminista; inversamente, o feminismo foi visto como uma ideologia burguesa, alienígena e abrigo para mulheres "liberadas" que usavam minissaia e praticavam o amor livre.

A crítica de Arnfred, sociologicamente fundamentada, incide então sobre as contradições do projeto modernizante da Frente de Libertação de Moçambique (Frelimo), aprisionado por determinada compreensão das relações de gênero, em grande medida devedora da formação inicial das subjetividades e dos valores dos principais líderes frelimistas, educados em missões cristãs. Como Eduardo Mondlane, primeiro presidente da Frelimo, educado na missão suíça de Rikatla, onde cem anos antes foi professor e diretor o etnólogo missionário Henri Junod. ${ }^{2}$ Poderíamos sintetizar o conteúdo do livro a partir de três eixos: gênero e modernização; limites do feminismo ocidental; e sexo subversivo. A participação da autora na conferência extraordinária da OMM foi um divisor de águas. A compreensão êmica sobre o papel dos ritos de iniciação, e de outras práticas tradicionais, 
pôde ser confrontada com o ponto de vista desenvolvimentista e nacionalizante do socialismo frelimista. As mulheres com quem a autora havia conversado nas inúmeras sessões preparatórias para o encontro defendiam com vigor práticas tais quais os ritos iniciação prevalecentes notadamente na região norte do país, área tradicional de grupos matrilineares, pertencentes ao chamado matriliny belt da África Austral. ${ }^{3}$ A autora, a partir desse diálogo, passou a ver os ritos como espaços de autonomia feminina, enraizada em estruturas sociais e na cultura autônoma dos povos Yao ou Makhua. Dessa forma, a modernização proposta pela Frelimo implicaria desorganização das estruturas tradicionais de poder feminino em benefício de um projeto nacional (unificador) e racional (modernizante), refundando as práticas de gênero de base matrilinear, encontradas no norte, em torno da invenção da família nuclear monogâmica na qual o pai/marido seria o chefe da família. Nas palavras da autora:

Matriliny and matrilocality is source of authority for women. But this is not how Frelimo and OMM see it, and they not defend it. In fact, Frelimo and OMM promote patriliny, not explicit but as a product of their general policy which centered on the promotion of the nuclear family. (p. 30)

O projeto socialista da Frelimo e, nesse caso, como a autora aponta, a modernização seriam inconciliáveis com o poder da mulher. A nova ordem social, a "sociedade de novo tipo", de que nos falam os documentos da Frelimo deveria ser uma ordem na qual o poder masculino pareceria efetivamente representar a modernidade e o progresso, enquanto formas não ocidentais e não patrilineares pareceriam representar o atraso.

A modernização econômica, imaginada no período heroico do socialismo como planificação centralizada da economia, implicava a transformação de economias de subsistência ou baseadas na dádiva, em economias do dinheiro, voltadas para o mercado ou para a troca de mercadorias. Ora, a participação da mulher na produção agrícola de subsistência era fundamental, além de culturalmente regulada, principalmente nas regióes matrilineares onde, como em outros contextos, observaríamos articulação entre o papel da mulher como reprodutora da vida humana e seus poderes presumidos sobre a fertilidade de um modo geral. Tal modernização, monetarização, de gênese anterior ao período da Independência implicou a desorganização de modos tradicionais de autoridade, política $e$ de gênero, na medida em que permitia, via incor- poração no mercado de trabalho transnacional (o trabalho nas minas de África do Sul), a individualização de homens jovens e sua capitalização, digamos assim, processo brilhantemente estudado por Ruth First e sua equipe. ${ }^{4}$

O entendimento da autora, produzido nas discussões e nos debates com as mulheres moçambicanas, a levou a reconsiderar o feminismo ocidental e a levar em conta a importância e a radicalidade das contribuições africanas à crítica feminista. Desse ponto de vista, a ideia de que a subordinação da mulher é universal e uniforme deveria ser revista, à luz da crítica às mesmas pretensões de universalidade do pensamento ocidental estabelecido. Não que a autora (ou eu mesmo) negue de modo absoluto as condições de opressão e desvantagem feminina, mas desconfia de como conceitos e categorias produzidas sob a égide universalista do pensamento pós-iluminista europeu podem dar conta das sutis distinções de poder e das hierarquias complexas encontradas em outros contextos. Apoia-se em grande medida, nesse caso, na contribuição de pesquisadoras africanas, particularmente em Ifi Amadiume e Oyèronké Oyewùmí. ${ }^{5}$ Notadamente, a compreensão é de que a modernização/ocidentalização cria em África as dissimetrias de gênero e a própria prevalência de categorias de gênero, que, como insiste Amadiume, ${ }^{6}$ não existiriam na tradição Igbo que ela estuda e à qual ela própria pertence.

A partir da crítica ao "gaze of modernity" encontrado em Simone de Beauvoir, Arnfred desvela como está sedimentada a ideia de que a mulher é o "Outro" por excelência e, mais, como as mulheres terceiro-mundistas (ou pós-coloniais) seriam superoutros e superexploradas, como se a subordinação feminina pertencesse à tradição e ao passado (e à África ou "naturvölker"7), enquanto a emancipação da mulher ou "gender equality, as the current terminolgy has it - belongs to modernity and to the future" (p. 107). Assim, vemos mais uma vez a identificação das estruturas sociais pré-modernas como fonte de todo atraso e opressão; e a modernização como intrinsecamente libertadora. Ora, o que a história da modernização revolucionária moçambicana mostra, e a autora demonstra isso amplamente é que o processo de modernização pode provocar tanta ou maior exclusão que padrões vistos como tradicionais. A crítica pós-estrutural de Butler $^{8}$ encontra assim na evidência etnográfica e na obra de autoras africanas que questionam - paradigma universalizante das relações de gênero correspondência inesperada, como aponta Arnfred. 
Por fim, papel da sexualidade, do desejo e, porque não dizer, da licenciosidade, tal qual a autora pôde flagrar e experimentar em meio às mulheres Makhua e seus ritos de iniciação e técnicas corporais, como o alongamento dos lábios vaginais com fins eróticos e estéticos. De modo corajoso e inovador, a autora aponta ainda como as mulheres "tradicionais" podiam fazer uso da sedução, do desejo e dos poderes sexuais para fazer políitica, tanto em uma dimensão intragênero, salientando-se o poder das mais velhas sobre as mais jovens, mas também intergêneros, desafiando o poder masculino com as artes do sexo e do desejo. Ao arrepio da pregação cristã e da moral revolucionária da Frelimo, demonizava-se a sexualidade da mulher e via-se, por exemplo, nas prostitutas, especialistas da ars erótica, a imagem incorporada da devassidão e degradação moral do colonialismo. ${ }^{9} \mathrm{O}$ desprezo, a culpa e o medo com que a políitica feminista ocidental enxerga o sexo, o erótico, a pornografia e a licenciosidade/devassidão poderiam eventualmente fazer sentido nos quadros da sociedade mercantil ocidental, mas fariam de fato sentido na situação matrilinear africana? Ou mesmo em outros contextos pós-coloniais?

O livro é muito rico em dados sociológicos e etnográficos aos quais obviamente não posso fazer justiça aqui, aborda uma variedade de questões com rigor e comprometimento e faz isso a partir de uma perspectiva engajada e crítica que implica a relativização das posições conceituais, políticas e mesmo subjetivas da própria autora, representando nesse sentido uma contribuição fundamental para os estudos de gênero em África, mas também para a própria reconceituação do feminismo em tempos de descolonização intelectual.

\section{Notas}

1 Como aponta Isabel Maria Casimiro (2005), o Destacamento surgiu em 1965 a partir de reinvindicação das próprias mulheres, apesar de a informação oficial afirmar que o Destacamento foi criado pelo comitê central em outubro de 1966. Arnfred, entretanto, aponta a criação do Destacamento em 1967.

2 Patrick HARRIES, 2007; Henri JUNOD, 2009; e Nadja MANGHEZI, 1999

${ }^{3}$ Audrey Isabel RICHARDS, 1974.

${ }^{4}$ Ruth FIRST, 1998

${ }^{5}$ Ifi AMADIUME, 1998; e Oyèronké OYEWÙMÍ, 2005.

${ }^{6}$ AMADIUME, 2005.

7 Os chamados "naturvölker - ou "povos da natureza", como os apelidava Karl Weule (2000), permaneceriam estacionados naquilo que F. Engels e L. H. Morgan chamaram de "direito materno" (Friedrich ENGELS, 2009). 8 Judith BUTLER, 2003
${ }^{9}$ Como Samora Machel insiste tantas vezes comparando prostitutas a vermes e pragas. (na verdade em outros textos e discurso não citados para não sobrecarregar a bibliografia).

\section{Referências}

AMADIUNE, Ifi. Male Daughters, Female Husbands: Gender and Sex in an African Society. London/New Jersey: Zed Books, 1998.

. "Theorizing Matriarchy in Africa: Kinship Ideologies and Systems in Africa and Europe." In: OYÊWÙMÍ, Oyèronké (Ed.). African Gender Studies: A Reader. London: Palgrave, 2005. p. 83-98.

BUTLER, Judith. Problemas de gênero: feminismo e subversão de identidade. Rio de Janeiro: Civilização Brasileira, 2003.

CASIMIRO, Isabel Maria. "Samora Machel e as relações de gênero". Estudos Moçambicanos, Maputo, n. 21, p. 55-84, 2005.

ENGELS, Friedrich. A origem da família, da propriedade privada e do Estado. São Paulo: Escala, 2009.

FIRST, Ruth. O mineiro moçambicano: um estudo sobre a exportação de mão de obra em Inhambane. Maputo: Centro de Estudos Africanos, 1998.

HARRIES, Patrick. Junod e as sociedades africanas: impacto dos missionários suíços na África Austral. Maputo: Paulinas, 2007.

JUNOD, Henri. Usos e costumes dos Bantu. Campinas: UNICAMP, 2009.

MACHEL, Samora. "A libertação da mulher é uma necessidade da revolução, garantia de sua continuidade, condição de seu triunfo". Coleção Estudos e Orientações, n. 4, Frelimo: CEA - UEM, 1974.

MANGHEZI, Nadja. "Eduardo Mondlane nos Estados Unidos da América (1951-1961)". Estudos Moçambicanos, Maputo, n. 17, p. 7-34, 1999.

OYÊWÙMÍ, Oyèronké (Ed.). African Gender Studies: A Reader. London: Palgrave, 2005.

RICHARDS, Audrey Isabel. "Alguns tipos de estrutura familiar entre os bantos do centro". In: RADCLIFFE-BROWN, Alfred Reginald; FORDES, Daryll (Org.). Sistemas políticos africanos de parentesco e casamento. Lisboa: Fundação Calouste Gulbekian, 1974. p. 281-338.

WEULE, Karl. Resultados científicos de minha viagem de pesquisas etnográficas no sudeste da África Oriental. Maputo: Ministério da Cultura, Departamento de Museus, 2000.

Osmundo Pinho

Universidade Federal do Recôncavo da Bahia 